المؤتمر العلمي الاولي الحادي عثر

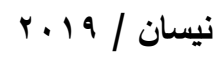

جامعة واسط

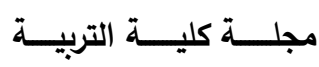

التعريف بالأرشيف العثماني وأهمية في دراسة التأريخ

م.م. أشرف سعدون طه

جامعة غازي عنتاب الحكومية ـ تركيا / كلية الأداب / قسم اللغة التُركية

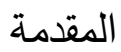

يحوي دائرة الارشيف العثماني في مبناه الجديد بالعاصمة اسطنبول مئات الالاف من المخطوطات والوثائق التي تعتبر ارشيف الدولة العثمانية على مدى اكثر من خمسة قرون، وما يهمنا من هذا الارشيف الحصول على معلومات عامة من الارشيف وما تحوية من مخطوطات ووثائق يساعد الباحث في الوصول الحقائق التاريخة بشكل سهل.

$$
\text { أهمية البحث: }
$$

بما أن الوثائق كتبت من قبل أفراد الجيش وكتبة الدولة والمفتشين ولأنهم موظفون رسميين فكانوا ملزمين بتقديم معلومات صحيحة.لانها تتعلق بأسرار الدولة وأمنها فكان من واجبهم الأخلاقي والأداري الأهتمام بنقل الحقائق وتدوينها كما هي، ولهذا السبب يعتبر الوثائق مادة علمية مكتملة يعتمد عليها في جميع الدراسات وبالأخص دراسة التأريخ. الهدف من البحث:

يعتبر وثائق الأشيف العثماني مصدرا مهما لطلبة الدرسات العليا في مختلف الأختصاصات وعلى مقدمتها دراسة التأريخ حيث يعتبر مصدرا غنيا بالمعلومات الموثقة عن تأريخ المنطقة العربية. دراسة وثائق الأرشيف العثاني يمكنها أن توحد الجهود العلمية في جميع المجالات الدراسية ، وخاصة حيث بدات أهتمام البلدان العربية تتوسع في الأونة الأخيرة لدراسة التأريخ ومعرفة 
المؤتمر العلمي الاولي الحادي عثر

ن بيسان / 19

جامعة واسط

مجلــــة كليــــة التربيــــة

موضوعتها ولأن الأرشيف العثماني يحمل معلومات مهمة وكثيرة أصبح مثار أهتمام كثير من الباحثيين.

الأرشيف العثماني :

هو الأرشيف العالمي الذي يتتاول تاريخ الدولة العثمانية من نشأتها عام 9979ه (99 (م) إلى

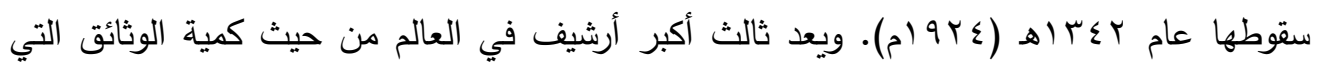
يضمها.

الأرشيف كلمة يونانية الأصل وتعني الوثائق الرسمية، وتعني أيضا المكان الذي تحفظ فيه مجموعة الأوراق التابعة لمؤسسات الدولة الرسمية أو الخاصة .

الأرشيف هو ايضا ذاكرة الأمة، حيث يتعذر فهم حياة من فقد ذاكرته بشكل أو بآخر ، ومثل هذا الإنسان يحس بأنه لا نسب له ولا أصل، كذلك الدول والمجتمعات التي لا أرشيف لها أو ليست غنية بالأرشيف بالقدر الكافي هي أشبه بمن لا ذاكرة له. تبقى محرومة من المعلومات التي تتير لها وترشدها إلى طريق المستقبل ولذلك فإن أهمية الأرشيف في أمة من الأمم كبيرة جدا تأريخ تأسيس دائرة الأرشيف العثماني:

تأسس عام \乏乏 من قبل الصدر الأعظم مصطفى رشيد باشا باسم "خزينة الأوراق. بمدينة اسطنبول عاصمة الدولة العثمانية واكتمل بناء دائرة الأرشيف وتم أفتتاحة رسميا عام .101. وقد عرف عن العثمانيون قبل افتتاح دائرة الأرشيف أنهح كانوا يسجلون الوثائق في دفاتر معينة بهدف حماية الحقائق والحقوق بصورة عامة ويحفظونها بحرص شديد كي يرجعوا إليها بسهولة عند الحاجة

يقع مبنى الأرشيف العثماني في منطقة "كاغط خانه" التي تبعد عن مركز مدينة اسطنبول بنحو 10 كم. وهو مبنى كبير وذو طباع معماري إسلامي، ومجةز بأحدث التقنيات، ويعمل به فريق كبير من 
المؤتمر العلمي الاولي الحادي عثر

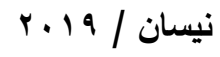

جامعة واسط

مجلــــة كليـــة التربيـــة

الباحثين والمتخصصين يزيد عددهم عن .ـ شخص. وتمر عملية التصنيف بمراحل حتى تصبح الوثيقة صالحة للاستعمال. وقد أنتهجت أساليب حديثة ومتطوّرة في هذه العملية، فالباحث اليوم يمكنه البحث في أجهزة الكمبيوتر الموضوعة في قاعة كبيرة وفسيحة، والاطلاع على مختصرات للوثائق

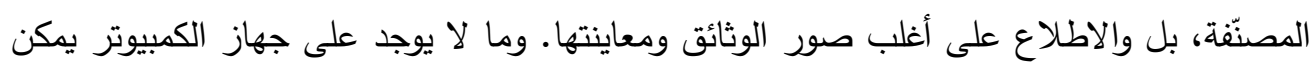
طلبه من المخزن، وفي خلال ساعات يكون بوسعه الاطلاع عليها في نسخها الورقية الأصلية. يوجد فريق من المتخصصين في ترميم الوثائق التي اهترأت وأصبحت مهذّدة بالتّلف، وهذا الفريق

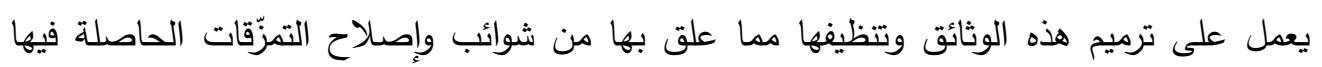

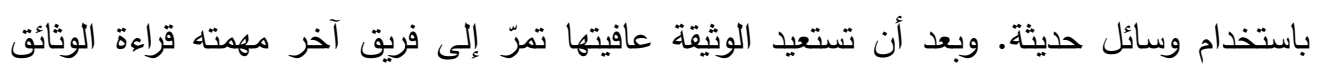
وفهمها ووضع ملخص لكل وثيقة. ويحتوي الملخص على معطيات دقيقة عن الوثيقة لكي يتمكن

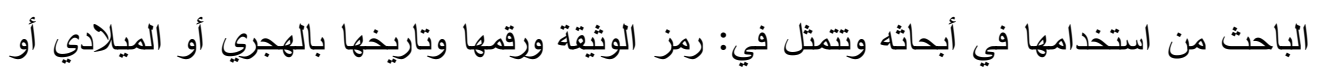
الزّومي ثم فقرة فيها المحتوى العام للوثيقة.

بعد ذلك يتم وضع صورة لهذه الوثيقة في جهاز الكمبيوتر مع ما يتعلق بها من معطيات. وبذلك

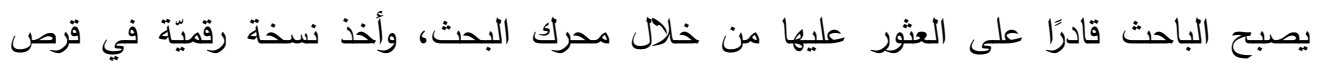
مضغوط. وتجدر الإثارة إلى أنّه بإمكان أي شخص الدخول إلى موقع الأرشيف العثاني والتسجيل

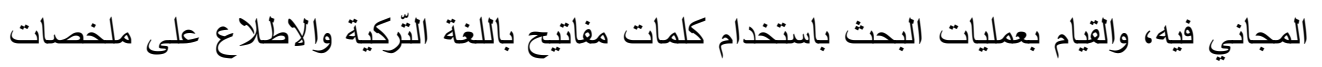

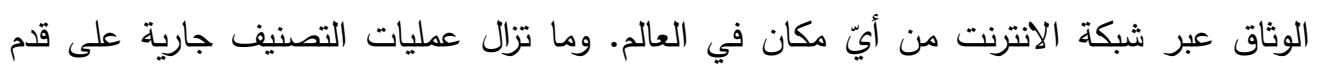

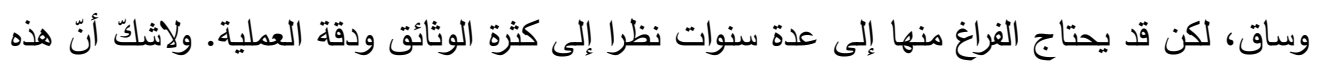

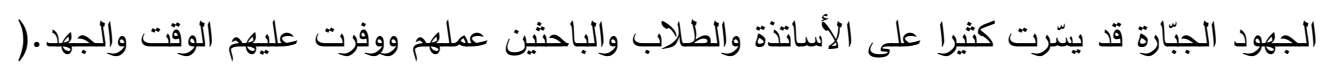

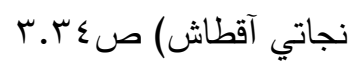


المؤتمر العلمي الاولي الحادي عثر

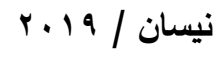

جامعة واسط

مجلــــة كليـــة التربيـــة

خسارة وثائق من الأرشيف العثماني:

في عام اب9 (، باعت الحكومة التركية كميات ضخمة من الوثائق الأرشيفية العثمانية إلى مصانع الورق في بلغاريا،لاستخدامها في تدوير نفايات الورق، وتم نقلها في عربات القطار .

ومنذ ذلك الوقت، تختزن المكتبة الوطنية في العاصمة البلغارية صوفيا كنوزا من الوثائق والمراجع والمخطوطات العثمانية النادرة.

تضم هذه المكتبة في بلغاريا ملايين الوثائق العثانية، وبينها أكثر من • 17 ألفا من السجلات، وألفا من الدفاتر العثمانية، وما يزيد عن مليون من الوثائق الفردية.

كما تضم ما لا يحصى من دفاتر الأوقاف من جميع ولايات الدولة العثانية فيما بين القرنين الخامس عشر والعشرين. وتضم بالإضافة إلى ذلك مخطوطات باللغات العربية والفارسية والتركية، كما تضم الأرشيف التاريخي البلغاري في المكتبة مقتنيات منزلية يعود معظمها إلى القرن التاسع عشر .

في عام اسب9 وفي إطار البرنامج السياسي للحكومة التركية القائم على رفض واستبعاد الماضي

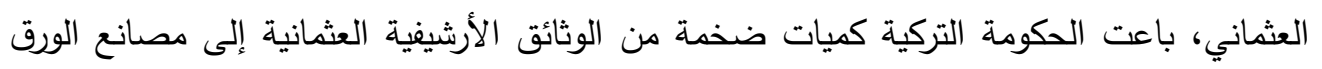
في بلغاريا لاستخدامها في تدوير نفايات الورق. وقد عرف هذا الحدث في التاريخ التركي باسم حادثة

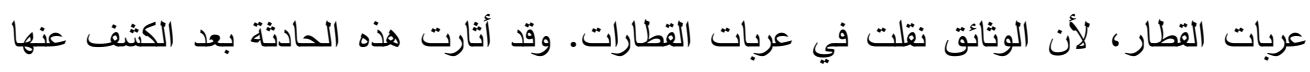
جدلا واسعا بين العلماء والسياسيين الأتراك. وعندما أدرك موظفو الجمارك البلغارية أن هذه المواد هي لهات

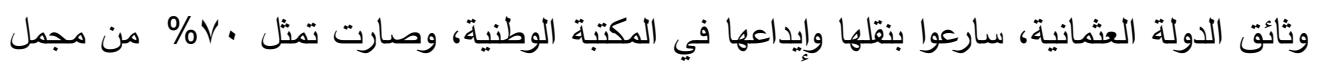
الوثائق الموجودة في قسم الوثائق الثرقية ـ ـ

تضم المكتبة الوطنية إحدى عشرة مجموعة من الوثائق تتوزع بين المخطوطات السلافية ووثائق مكتوبة بلغات أجنبية، فضلا عن مجموعة قسم الوثائق الثرقية التي تشمل أرشيفين رئيسيين: 
المؤتمر العلمي الاولي الحادي عثر

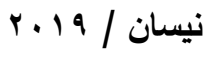

جامعة واسط

rion College

أرشيف الدولة العثمانية، ومجموعة مخطوطات شرقية. وفيما يلي أبرز المجموعات التي تفيد الباحثين في تاريخ الثرق الأوسط والدولة العثمانية. مراحل تصنيف وثائق الأرشيف العثماني:

بدأت أعمال التصنيف الأول مرة بتثكيل لجنة التاريخ العثماني برئاسة علي أميري أفندي عام

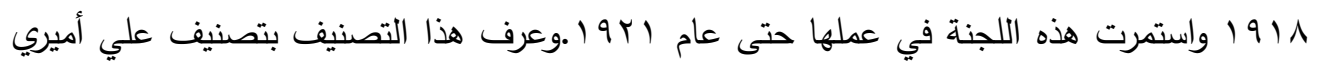
ويشمل الفترة بين الغازي عثمان والسلطان عبد المجيد على أساس التسلسل التاريخي للسلاطين. ويبلغ عدد الوثائق المصنفة ضمن هذا الإطار مائة وثمانين ألفا وسبعمائة وثيقة في ثلاثة وخمسين كتالوجا مكتوبا بالحروف العربية. وقد حولت فيما بعد إلى الحروف اللاتينية.

والتصنيف الثاني بدأ عام |9Y من قبل لجنة يرأسها المؤرخ التركي الثهير ابن الأمين محمود كمال. وهو تصنيف حسب المواضيع وشمل سبعا وأربعين ألفا ومائة وخمسة وعشرين وثيقة في ثلاثة وعشرين موضوع أساسي في الفترة بين القرنين الخامس عشر والتاسع عشر. وكتالوج تصنيف ابن الأمين الذي يبلغ عدد مجلداته تسعة وعشرين مجلدا كتب بالحروف العربية. وأكثرية وثائق هذا التصنيف تتعلق بالقرنين الأخيرين. وتوقفت عملية التصنيف بسبب ظروف حرب العالمية الأولى ويسى بحروب الاستقلال التركية.

التصنيف الثالث تمت بفضل الجهود التي بذلها كل من المعلم جودت وإبراهيم حقي القونوي واستمرت هذه الجهود حتى عام VI9 إ. بعد أن نال الأششيف حظه من السلبيات التي تعرض لها التراث العثماني في أوائل العهد الجمهوري وتوقفت أعمال التصنيف فترة من الزمن. بعد افتضاح أمر بيع

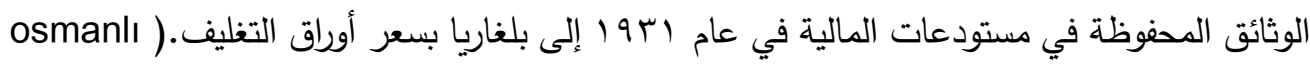
r 
المؤتمر العلمي الاولي الحادي عثر

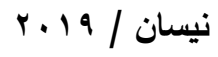

جامعة واسط

مجلــــة كليـــة التربيـــة

حجم وثائق الأرشيف العثماني: - (ل)

يقدر عدد وثائق الأرشيف العثماني ما بين مائة وخمسين مليونا ومائتين وخمسين مليونا أكثر من نصف هذا العدد من الوثائق التي تخص العالم العربي عموما ومنطقتي البصرة والحجاز بصورة خاصة

المصنف منها على شكل دفاتر عدد الدفاتر المصنفة في الأرشيف العثماني (9970V) مائة

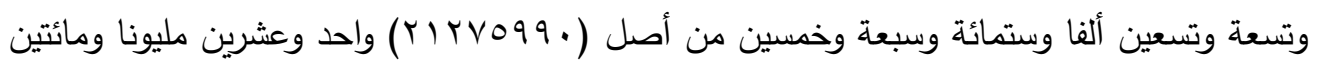
وخمسة وسبعين ألفا وتسعمائة وتسعين. كما بلغ عدد الوثائق المصنفة (اء) أربعين مليون وثيقة في ثمانية عشر مليونا وثلاثمائة وتسعة وخمسين وأربعمائة وثمانية وتسعين ورقة.(نجاة اقتاش 1914 ا-

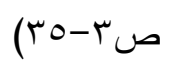
تصنيف وثائق الأرشيف العثماني على ثلاثة أقسام: القسم الأول

تصنيف الدفاتر ويقصد بالدفاتر السجلات المتسلسلة التي دونت فيها القرارات المتخذة في البيروقراطية

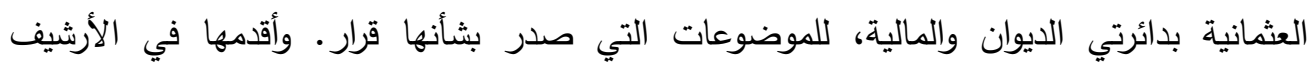
العثماني يعود إلى عام هبهه/ بr إم وهي الدفاتر الخاصة بالأراضي والتمليكات.

تنقسم دفاتر الأرشيف العثماني إلى أنواع كثيرة. منها:

دفاتر الديوان الهمايوني، التي تقع أيضاً على أنواع. منها: دفاتر المهمة، ودفاتر الأحكام، ودفاتر

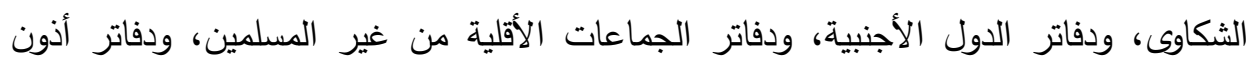
السفن، ودفاتر النفي والقصاص، ودفاتر التحرير .. إلخ.

دفاتر المالية المعروفة بالباب الدفتري، التي تنقسم إلى ستة وثلاثين نوعاً. منها: دفاتر حسابات الأناضول، ودفاتر العساكر المنصورة، ودفاتر روزنامجه الذي كان يتولَّى الحسابات اليومية لئل 
المؤتمر العلمي الاولي الحادي عثر

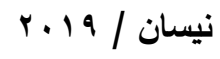

جامعة واسط

والأعمال الجارية في الباب الدفتري، ودفاتر الجزية، ودفاتر حسابات الحرمين الشريغين، ودفاتر الأوقاف، ودفاتر المعادن، ودفاتر التشريفات، ودفاتر الإنكشارية... إلخ.

دفاتر الباب العالي التي تتفرع إلى: دفاتر دائرة الصدارة، بمختلف أنواعها، ودفاتر أوراق الباب العالي التي تحوي كثيراً من الموضوعات الخاصة بالجزيرة العربية، ودفاتر الدوائر الأخرى التابعة للباب العالي.

دفاتر قصر يلدز بقسميها: دفاتر المعروضات، ودفاتر تصنيف يلدز •

دفاتر النظارات (الوزارات) والولايات والمفتشيات العامة والدوائر الحكومية الكبيرة. مثل: دفاتر نظارة الداخلية، ودفاتر نظارة الخارجية، ودفاتر نظارة الصحة، ودفاتر نظارة المعارف، ودفاتر

الولايات..إلخ ، ويبلغ عدد تلك الدفاتر بمجموع أنواعها ثلاثمائة ألف دفتر .

\section{القسم الثاني}

تصانيف وثائق الأرشيف العثماني ، وهي على ستة أنواع رئيسة:

ا . وثائق الديوان الهمايوني والباب الآصفي.

ץ. وثائق الباب الدفتري (المالية .

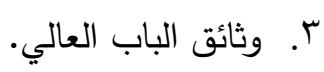

ع. ـ وثائق قصر يلدز .

๑. وثائق النظارات والولايات والمفتشيات العامة والدوائر الحكومية الكبيرة. T. وثائق التصانيف الأخرى. 


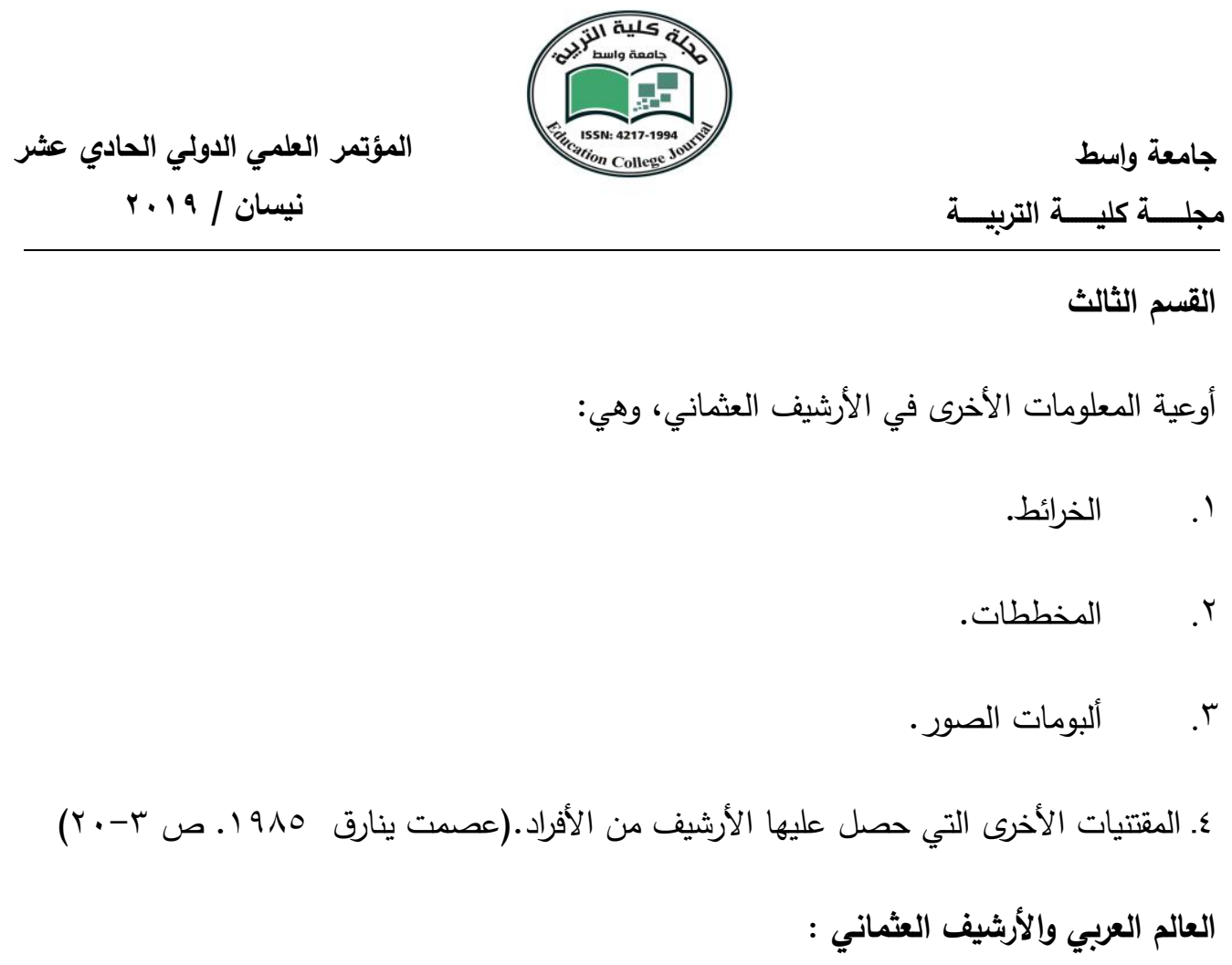

للأسف لا يوجد أي أهتمام بمجال البحوث الترّكية والعثمانية في جامعاتتا العربية، والدراسات التاريخية ذات نتائج ضعيفة إلى أبعد الحدود بسبب عدم معرفة الدارسيين للغة التركية ، واذا رأينا للاقسام التركية في الجامعات العربية تكون شبه معدومة او أنشئ قبل سنوات قليلة.

لكن هذا الأمر المجال يحتاج إلى دعم قوي من الدّولة، ويحتاج إلى برامج واضحة واستراتيجيات مدروسة لتكوين باحثين متخصصين في كل دولة عربية من أجل الاستفادة من هذه الكنوز مثلما يستفيد منها غيرنا. فمن أكبر عوائق البحث في هذا المجال هو الجهل باللغة التّركية، والتركية أداة مهمة بل وضرورية للولوج إلى عالم الوثائق. وتجدر الإشارة إلى أن الحكومة التركية توفر كل عام منحًا

كثيرة لجميع المستويات من أجل الدّراسة والبحث في الجامعات التّركية، والاستفادة منها ما تزال

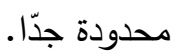


المؤتمر العلمي الاولي الحادي عثر

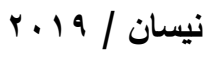

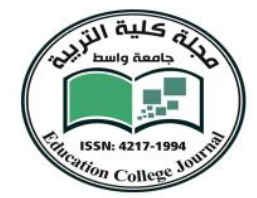

جامعة واسط

مجلــــة كليــــة التربيــــة

للأسف فالعالم العربي بعد الثّررات التي حدثت فيه يمرّ بموجة من العواصف الثّديدة، وشعوبه تكابد من أجل الحصول على حريتها وكرامتها التي أهدرت لسنوات طويلة، وكان الاهتمام طوال العقود الماضية منصرفا لمجالات أخرى غير البحوث العلمية، وكانت ثرواته محتكرة لدى قلة من المنتقعين الجاهلين الذين لا يعرفون للعلم قيمة ولا قدرًا.

\section{أهمية الأرشيف في دراسة التأريخ :}

إنّ الدارس للتاريخ في فترة العهد العثماني يجد أمامه عددا كبيرا من الوثائق المتتوعة موزعة على دور الأرشيف داخل الوطن العربي وخارجه، التي تكتسي أهمية كبيرة نظرا لتتوع موضوعاتها، فهي تتحدث لقضايا متعددة منها سياسية، عسكرية، اقتصادية واجتماعية. بما أن الوثائق كتبت من قبل أفراد الجيش وكتبة الدولة والمفتشين ولأنهم موظفون رسميين فكانوا ملزمين بتقديم معلومات صحيحة.لانها تتعلق بأسرار الدولة وأمنها فكان من واجبهم الأخلاقي والأداري الأهتمام بنقل الحقائق وتدوينها كما هي، ولهذا السبب يعتبر الوثائق مادة علمية مكتملة يعتمد عليها في جميع الدراسات وبالأخص دراسة التأريخ.

الوثائق هي مصادر حقيقة لانها نابعة من مصادر موثقة كتبت في زمانين ومكانين معلومين وتكون تحت سجل وقيد ورقة وتاريخ معلوم محدد باليوم والثهر والسنة

إضافة إلى كمية الوثائق التي يحويها الأرشيف العثماني وتنوعها، من حيث تعلقها بتاريخ البلاد التي دخلت تحت حوزتها، فإن الاهتمام الذي يوليه إيَّاه الباحثون من مختلف أنحاء العالم، لدليل واضح على أهميته، والدور المهم الذي يضطلع به في توفير المادة العلمية للحقبة التي يدرسها أولئك الباحثون.

وعلى الرُغم من الأهمية البالغة للأرشيف العثاني، والوثائق التي يحويها في الفترة الممتدة أربعة قرون

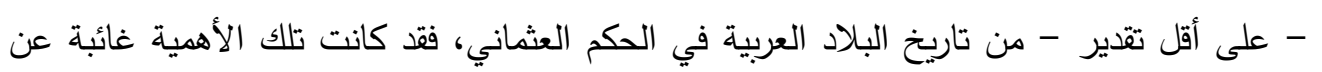


المؤتمر العلمي الاولي الحادي عثر

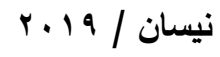

جامعة واسط

IISN: 4217-1994

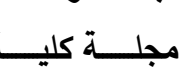

أنظار كثير من الباحثين الذين يبحثون في تاريخ البلاد العربية المعاصر، كما أن علاقة هذا الأرشيف بدور الأرشيف العربية كانت غائبة عن أنظار مسؤوليها أنفسهم، وكذلك عن أنظار الباحثين بشكل

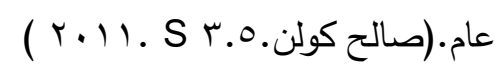

وثيقة تخص معركة كوت العمارة :

المقدمة :

العلاقة بين علم التاريخ والأرشيف وثيقة لا يمكن فك الارتباط بينهما. والأرشيف معين دائم تستمد منه عملية كتابة التاريخ غذاءها. ولذلك فإن وظيفتها هي أن تبقي على هذا المعين مفتوحا وأمينا ومناسبا لعملية كتابة التاريخ

يحتل موقع مدينة الكوت والمناطق المجاورة لها ، اهمية استراتيجة بالغة اضافة الى ما يتوفر فيها من خيرات وموارد طبيعية، جعلت اعدائها يتحينون الفرص لاعتداء عليها من اجل الهيمنة واستغلال ثرواتها والاستفادة من موقعها الجغرافي المطل على مدن رئيسة وذات مركز قيادي في تحديد مسار السلطات الحاكمة للمنطقة.

تعتبر وثائق الارشيف العثاني من بين المصادر الكتابية المهمة الخاصة بالتوثيق والارشفة الادارية لحقبة مهمة من تاريخ الوجود العثماني في المدن التي كانت خاضعة لسلطة الدولة العثمانية، والوثيقة التي تخص الدراسة تعود الى القرن الثالث عشر الهجري، وتحديدا با نيسان 019 (وعليه ستكون (başbakanlık osmalı arşivleri الدراسة.(r) 

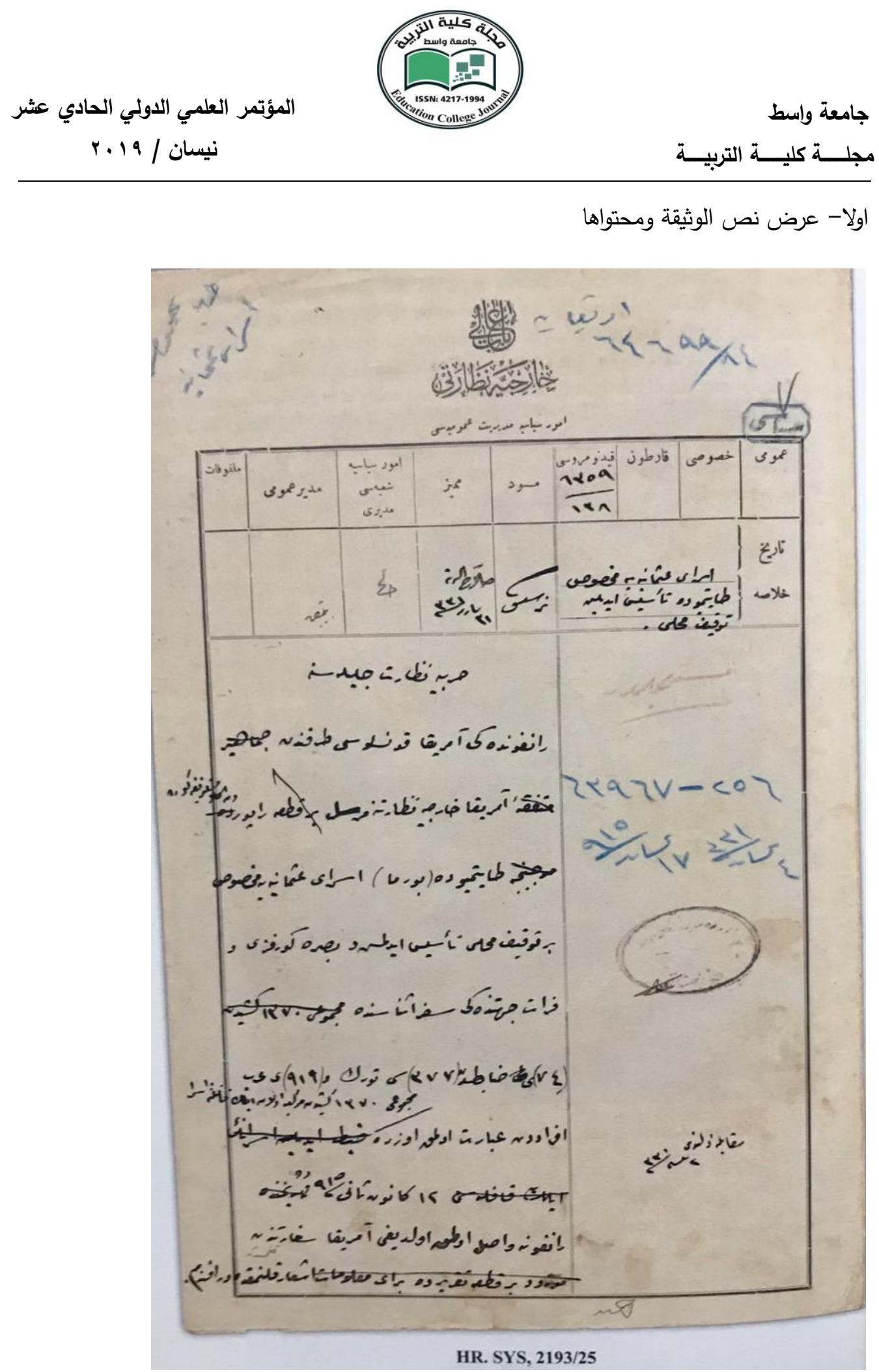


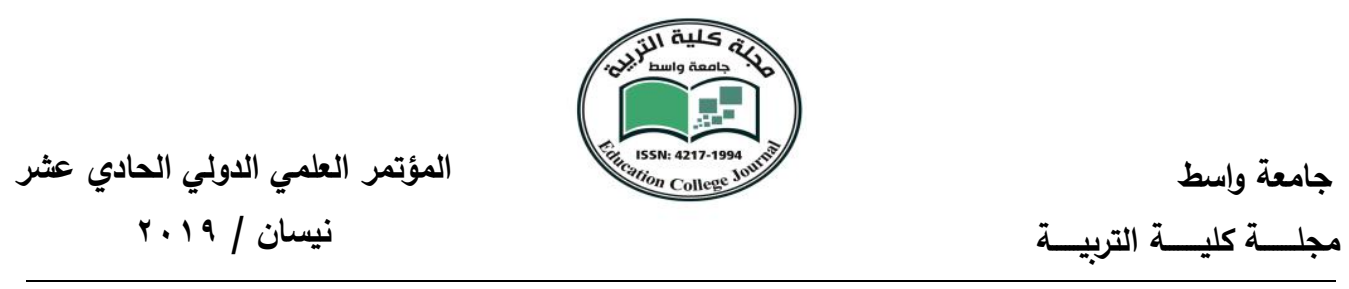

Irak cephesinde esir düşen bir osmanlı

askerlerin burmaya nakli

Basra Körfezi Ve fırat cevresindeki savaşlarda ingilizlere esir düşen $\vee$ 纟'ü subay rvv'si Türk ve q।q'u Arab efratdan oluşan toplam irv. kişilik ilk Osmanlı esir kafilesininBurma'nın Thayetmyo kentinde hazırlanan esir kampına götürüldükleri .

1r Nisan 1910

Hulâsa : Üserâ-yı Osmaniyyeye

mahsus

Thayetmyo'da te'sis edilen tevkif

mahalli

Bâb-ı Âlî

Hariciye Nezâreti

Umûr-ı Siyasiye Müdüriyet-i umumîyesi

Kayd numarası : 7 roq - ir

Tarih : $r$ Mart sene [ 1$]$ r

Harbiye Nezâret-i Celilesi'ne

Ranngon'daki Amerika konsolosu tarafından Amerika Hariciye Nezaretine mürsel rapordan anlaşıldığına göre Thayetmyo ['da ] (Burma) üsera-yı Osmaniyye'ye mahsus bir tevkif mahalli te'sis edilmiş ve Basra 
المؤتمر العلمي الدولي الحادي عشر

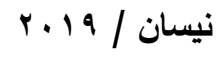

جامعة واسط

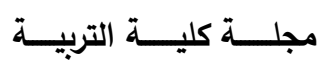

Körfezi ve Fırat cihetindeki sefer esnasında $\vee \_$'ü zabitden rVv'si Türk ve 9) 9'u Arab efraddan ibaret olmak üzere mecmû'u Irv. kişiden mürekkeb olan ilk kafile-i üserâ Ir Kânûn-ı Sânî sene [1] 910'te Rangon'a vasıl olduğu Amerika Sefâreti'nden iş 'âr kılımakdadır , efendim .

HR.SYS, Y I 9 / Y

ثالثا- تحليل نص المخطوطة والوقوف على اهم محتوياتها.

$$
\text { ا-تحليل المعلومات الواردة في الوثيقة: }
$$

ان الوثيقة التي بين أيدينا تتضمن في فحواها العام على معركة جرت بين الدولة العثمانية من جهة والقوات الانكليزية في منطقة اسمها كوت العمارة ، وحسب الوثيقة فان الانكليز قاموا بأسر اكثر من فن فين الف جندي تركي ومقاتل عربي وتم تسفيرهم الى معسكر لأحتجاز الاسرى في بورما. ץ- ترجمة المخطوطة الى اللغة العربية حرفيا وبالمعنى العام.

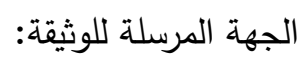

وزارة الخارجية مكتب مديرية الأمور الثؤون السياسية العامة الجهة المستلمة للوثيقة: وزارة الحربية (الدفاع)

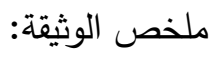
نقل الجنود العثمانيين الذين وقعوا في الاسرى من جبهة العراق الى بورما تاريخ الوثيقة: سا نيسان 1910 نص الوثيقة: - 20 - 20 


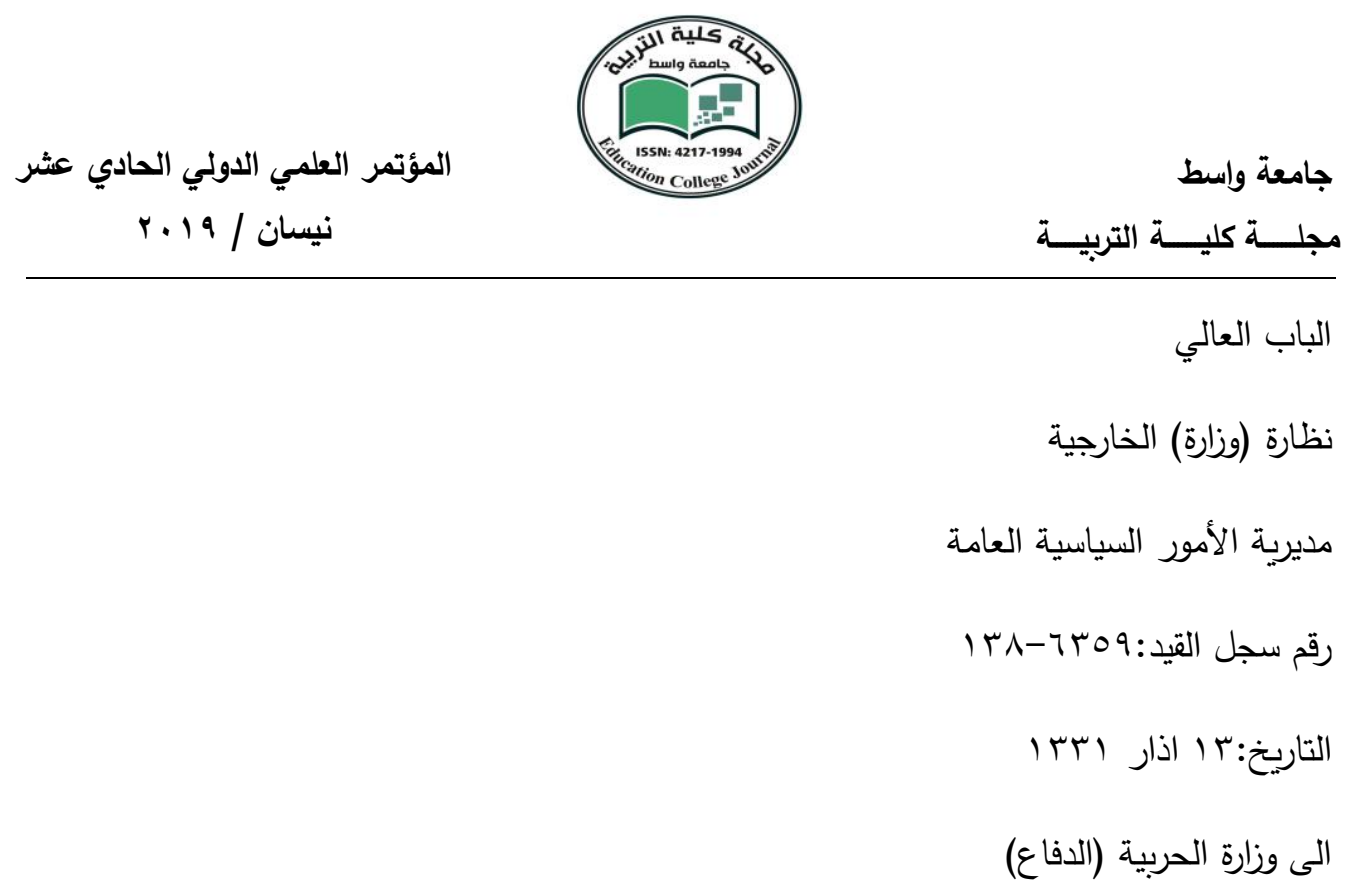

حسب التقرير الوارد من القنصلية الامريكية المتواجدة في مدينة رانكونا- بورما الى وزارة الخارجية الأمريكية والذي فهم منها انه تم أرسال (سوق) مجموعة من الاسرى العثانيين الى معسكر أنشئ

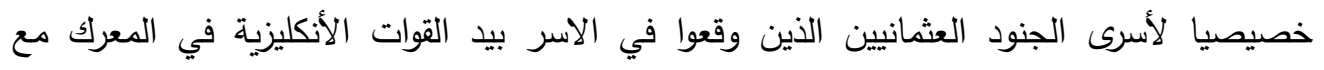
الانكليز في مدينة ثايتمويا و وعددم •VV إنسكري من الجيش العثماني بيد القوات الانكليزية في

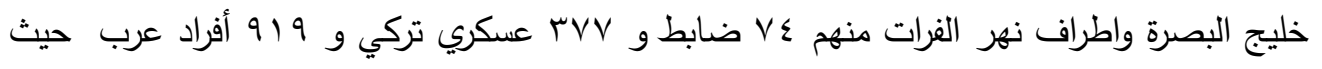
تم الحاقهم بقافلة المتجهة الى معسكر الاسرى الذي تم انشائة خصيصا للاسرى بمدينة ثايتمايا في

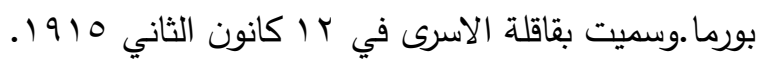

Or|r 9 ו Y HR.SYS, رقم وعنوان الوثيقة ا - أسماء المدن الواردة في الوثيقة:

$$
\text { د-البصرة }
$$




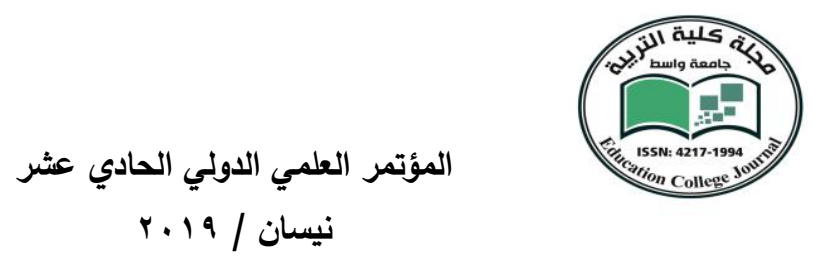

\section{جامعة واسط} مجلـــة كليــــة التربيـــة

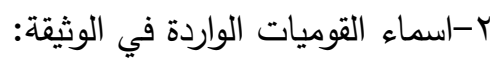

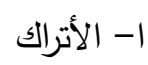

ب- العرب

ج-الأنكليز

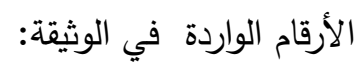

$v \leqslant-1$

$r v V-\varphi$

919-ج

أهم قضية وردت في نص الوثيقة:

الثيء اللافت للنظر هو ارسال الاسرى بورما ومن ثم مشاركة العرب من ابناء العراق معهم في الإني

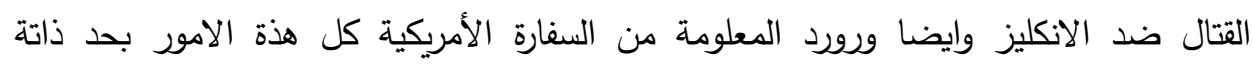
موضوع خاص لوحدهها.

الأسئلة التي يمكن استتاجها من الوثيقة:

بما أن الوثيقة تتحدث عن التأريخ فمن المؤكد ترد فيها اسئلة متعددة ومتتوعة تختلف بأختلاف المعلومات الوادرة في الوثيقة ويمكننا تلخيص الأسئلة كالاتي. ا- لماذا تم اختيار بورما في أقامة هذة المعكسر ام فعلا كانت موجودة ب- لماذا تم الحصول على المعلومة من السفارة الأمريكية

ج-العرب الموجودين من الجيش العثماني هل هم عراقييون حصرا وهل هم جنود رسميين ام مشاركين كاأفراد قبائل. 
المؤتمر العلمي الدولي الحادي عشر

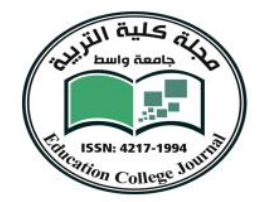

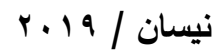

جامعة واسط

مجلــــة كليــــة التربيــــة

د-مامصير الأسرى هل بقوا هنالك بعد أنتهاء الحرب وبالأخص العرب منهم

الخاتمـة:

يعتبر وثائق الارشيف العثماني من بين المصادر الكتابية المهمة الخاصة بالتوثيق والارشفة الادارية لحقبة مهمة من تاريخ الوجود العثاني في المدن التي كانت خاضعة لسلطة الدولة العثمانية.

المغزى من البحث هو سرد بعض المعلومات التي تخص دائرة الارشيف العثماني من ناحية عدد وكمية ونوعية الوثائق الموجودة حيث يبلغ عدد الوثائق الموجودة في الارشيف مايقارب . ... 190 مليون وثيقة تخص مجالات ادارة الدولة العثمانية (العسكرية والداخلية والادارية والمالية والمدنية) موجودة في اسطنبول وفي انقرة.

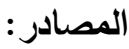

IILASIK Mah.Meltem Sok.No: صالح كولن .سلاطين الدولة العثمانية

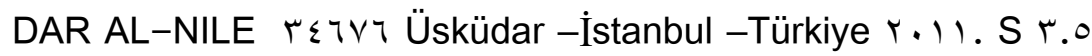

Başbakanlık Devlet Arşivleri Genel. Başbakanlık Osmanlı Arşivi Rehberi -r Müdürlüğü İstanbul $r .1 \vee$ yayin nu: $\leqslant \vee$. s $r . \varepsilon$

r- الأرشيف العثاني/ نجاتي آقطاش وعصمت بينارق ؛ ترجمة صالح سعداوي.- أسطنبول : مركز

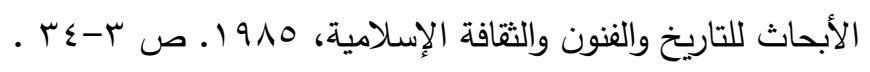

Başbakanlık Osmanlı Arşivi Rehberi.-Ankara: Başbakanlık Devlet Arşivleri Genel Müdürlüğü, 199 ص.

ه- نجاة اقتاش .الأرشيف العثاني فهرست شامل لوثائق الدولة المحفوظة في اسطنبول. مركز

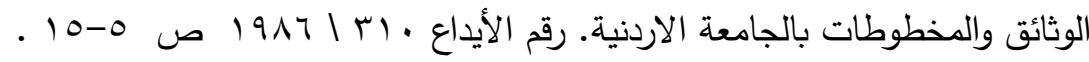

DEVLET ARŞIVLERİ GENEL MÜDÜRLÜĞÜ OSMANLI ARŞIVII DAİRE BAŞKANLIĞI YAYIN NO: I $\leqslant$ r.ISTANBUL. r • 17 s.or-or 